\title{
Patrimônio, cultura e iluminação: uma reflexão sobre o uso da luz no patrimônio cultural
}

Cultural heritage, culture and lighting: a reflection on the use of light in cultural
heritage.

\author{
Elandia Vieira de S. Thiago ${ }^{36}$ \\ Nadja de Carvalho Lamas ${ }^{37}$
}

Artigo recebido para publicação em Out./2013 e aceito para publicação em Maio/2014.

\section{RESUMO}

$\mathrm{Na}$ contemporaneidade, com a transformação social no âmbito global, o uso da luz no conjunto patrimonial e seus meios de interação com a sociedade, propõem novas formas de intervenção tecnológicas, que instigam novos olhares diante da interação com a luz sobre o patrimônio cultural. $E$ a requalificação dos espaços públicos patrimonializado das cidades inseridos num contexto coletivo de interesse comum, traz uma nova leitura e interesse pelo local. As contribuições sobre o uso de instrumentos que coordenam as tomadas de decisões no planejamento do objeto a ser iluminado, pode adotar a presença de elementos visuais para o entendimento da imagem urbana noturna. $A$ discussão sustenta-se em conceitos, da tecnologia, do patrimônio cultural e da sustentabilidade, bem como de sua relação com as políticas de preservação e comunicação do conjunto patrimonializado das cidades.

Palavras-chave: Patrimônio cultural. Cultura. Iluminação. Sustentabilidade.

\section{ABSTRACT}

In contemporary times, with social transformation in the global context, the use of light and its means of interaction with society, provide new forms of technological intervention that instigate new insights on the interaction with the light on cultural heritage. And the redevelopment of public heritage spaces of the cities inserted into a collective context of common interest, brings a new reading and interest in the site. The discussion holds on concepts, technology, cultural heritage and sustainability, as well as its relation to the politics of preservation and communication of the cities. The discourse is sustained by meeting the issues of historical, artistic and sustainable commitment, able to contribute new insights in project valuation of monuments to the city through its prominence, with the guidance director lighting plan.

Keywords: Cultural heritage. Culture. Lighting. Sustainability.

\footnotetext{
${ }^{36}$ Formada em História pela Universidade da Região de Joinville (Univille) e pós-graduada em Gestão Empresarial e Educacional pela Associação Catarinense de Ensino (ACE), gerencia projetos de iluminação do patrimônio cultural na empresa italiana Brasita, representante de fábricas no Brasil.E-mail: elandiav@hotmail.com.

${ }^{37}$ Doutora em Artes Visuais pela Universidade Federal do Rio Grande do Sul (UFRGS), em 2005, fez doutorado sanduíche pela Université Paris 1 (Panthéon Sorbonne). É mestre em Artes Visuais pela UFRGS (1996), especialista em arte na educação, pela Faculdade de Artes do Paraná (FAP) (1992), e graduada em Administração pela Fundação Educacional da Região de Joinville (Furj) (1981). Atua como professora titular da Univille, no curso de graduação em Artes Visuais, nas disciplinas de História da Arte, Estética e Teoria e Crítica da Arte, e como professora no Mestrado em Patrimônio Cultural e Sociedade, também da Univille, nas disciplinas Estética e Pensamento Contemporâneo.
} 


\section{A PATRIMONIALIZAÇÃO DA CULTURA NO TEMPO PRESENTE}

O espaço urbano, onde permeiam conceitos sobre patrimônio, cultura e iluminação, apreende relações e modos diferenciais de apropriação no espaço. Com o propósito de interagir com os significados artísticos, culturais e históricos, possibilita perpassar a cidade por meio do convívio da experiência dos seus habitantes, introduzindo o sentido da sua materialidade. Desse modo, os referenciais simbólicos representados no conjunto patrimonial são evidenciados com a luz, conforme uma dimensão qualitativa, para ampliar o pensamento sobre a dinâmica da vida social.

O papel da iluminação ganhou atenção em função do avanço tecnológico. Antes a luz tinha caráter funcional, priorizando apenas as condições de deslocamento. Hoje, a discussão das cidades sustentáveis incentiva o sentido de conservação e preservação ambiental. Essa conscientização recria identidades para fortalecer o convívio local, mas para que esse plano seja exercido, na opinião de Sachs (2002, p. 31), é necessário, "portanto, uma abordagem histórica e interdisciplinar, na qual cientistas naturais e sociais trabalhem juntos em favor do alcance de caminhos sábios para o uso e aproveitamento dos recursos da natureza, respeitando sua diversidade".

O projeto apresentado na imagem iconográfica, traz a iluminação do Castelo de Baradello, em Como (Itália). Trata-se de uma torre do século XII, iluminada com a tecnologia LED, reduzindo os gastos com a manutenção e com o consumo de energia, além de evitar o desperdício de energia com a emissão de calor produzida por lâmpadas de vapor metálico.

Figura 1 - Castelo de Baradello, em Como (Itália)

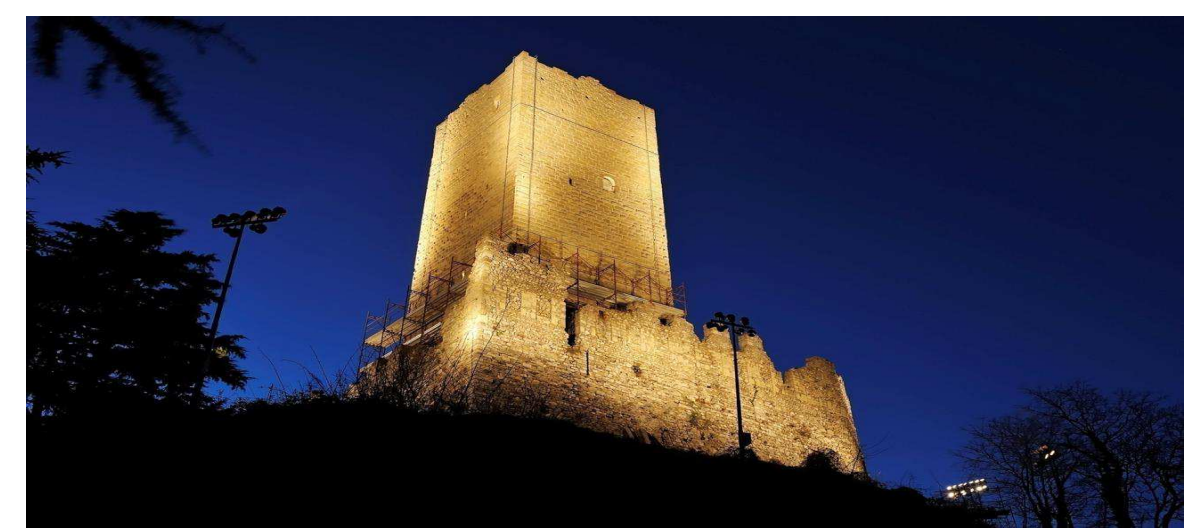

Fonte: Projeto de iluminação da iGuzzini. Disponível em:

<http://catalog.iguzzini.com/projects.aspx>. Acesso em: 3 set. 2012 
Com essa perspectiva, é importante integrar todas as contribuições da dimensão da sustentabilidade, afinal a luz pode ser usada como instrumento na concepção do espaço, com base em tecnologias alternativas. A valorização do patrimônio cultural no processo de requalificação das cidades ganha cada vez mais expressão na gestão dos espaços públicos, em decorrência do reconhecimento de seu valor cultural e econômico na dinâmica da vida urbana, ao considerar a luz um instrumento de comunicação estética que revitaliza espaços públicos.

Para uma nova leitura dos elementos que compõem o espaço cultural, é possível contar com instrumentos como projetos luminotécnicos fundamentados em um plano diretor de iluminação que siga uma metodologia adequada para a aplicação da luz sobre o ambiente patrimonializado. A ideia é dar, com o uso da luz, melhor visibilidade noturna ao patrimônio, com a possibilidade de gerar retorno econômico e social para a sociedade. Intenciona-se aqui apresentar meios com a finalidade de se criar um novo cenário para a requalificação da luz nos espaços públicos patrimonializados.

Nessa perspectiva, são elencadas as potenciais contribuições da iluminação artificial, como o conforto visual e um ambiente seguro para a interação da sociedade na experimentação do patrimônio cultural na paisagem noturna. Pretendem-se inserir nos espaços patrimonializados novas ações sustentáveis que promovam o patrimônio cultural para o desenvolvimento econômico e social, com novas abordagens do uso da luz que possibilitam enaltecer os patrimônios culturais e, concomitantemente, valorizar a cidade.

O plano diretor de iluminação de uma cidade deve nortear as propostas de valorização do patrimônio cultural, promovendo a conscientização da importância da preservação e, com isso, elevar questões de desenvolvimento social, cultural e econômico do município. Esse plano de ação deve ser prescrito e adaptado às características do espaço público, com a equiparação ao usuário e suas características culturais. O uso do plano diretor como instrumento norteador tem como função orientar as práticas dos profissionais ligados à iluminação dos monumentos, para que tenham diretrizes eficientes para o desenvolvimento do projeto. Os planos diretores de iluminação urbana devem levar em consideração o seu contexto cultural, a fim de valorizar os ambientes urbanos integrados com referenciais culturais do patrimônio cultural em questão: "O plano diretor de iluminação precisa apresentar concordância em relação aos pressupostos de 
preservação da ambiência urbana, ajustando-se à política de salvaguarda do sítio histórico" (GONÇALVES, 2005).

Os conceitos e princípios que direcionam a concepção técnica e visual levam em conta a harmonia do conjunto, a requalificação do espaço e a interação da luz com a paisagem.

O patrimônio cultural é presente e, para referenciar a cultura na utilização dos espaços culturais, possui singularidades históricas e arquitetônicas. A requalificação urbana desses espaços possibilita a reconfiguração da sua função memorial, embora os projetos de iluminação tenham conquistado a intenção de conservar e valorizar o conjunto patrimonial no contexto urbano. A concepção de alguns projetos não atende ao sentido do bem patrimonial. Algumas intervenções operam os marcos patrimoniais de forma individualizada, valorizando apenas pontos da imagem noturna da cidade.

A cultura atual está sendo confrontada com o valor da imagem produzida pela mídia. Assim, os patrimônios culturais correm o risco de virar um produto cênico, distanciando-se do significado do patrimônio cultural, originalmente relacionado à ideia de transmitir a identidade cultural para as gerações futuras. Hoje, com a velocidade no trânsito das informações, mostram-se distantes da realidade cultural. Para atingir a compreensão de sua construção é preciso explicar a si mesmo por intermédio do outro. Conforme Eagleton (2005, p. 139), "se o 'outro' encontra-se além da minha compreensão, não é por causa da diferença cultural, mas porque ele é, afinal de contas, ininteligível para si mesmo também". Com a diversidade nasce a possibilidade de reinvenção da cultura. Muitas vezes pela incapacidade de nos separar das necessidades naturais, somos levados a desenvolver uma política que contemple as mais diversas formas de expressão dos bens da humanidade.

Diante desse quadro interpretativo proposto por Candau (2011), não é possível haver identidade sem memória, pois a lembrança ou o esquecimento propicia a autoconsciência que representa o indivíduo, e o vínculo com o presente passa a dar fundamentação às identidades culturais. Por outro lado, os esquecimentos provocados pela ação contemporânea de tudo armazenar, sem o estabelecimento de uma valorização, estão provocando uma grande crise de identidade, desnaturalizando os acontecimentos que dão sentido forte ao vínculo de pertencimento.

Logo, o conceito de patrimônio cultural está cada vez mais associado às necessidades de melhoria da vida nas cidades, e assim a memória compartilhada, 
construída segundo as carências e os interesses do presente, determina o conteúdo dos discursos. Os valores patrimoniais mudam com o tempo e com as sociedades e, em sua construção, apresentam momentos comuns entre a história, arte ou cultura. Nas questões ligadas à preservação dos bens patrimoniais, surgem possibilidades atuais de desenvolvimento sustentável atreladas à iluminação do patrimônio cultural, a fim de contribuir para o desenvolvimento social e econômico, além de propiciar meios sustentáveis para a preservação dos bens culturais.

Nesse caso a política de gestão do patrimônio cultural aponta para mudanças conceituais e metodológicas significativas no que se refere à requalificação urbana dos espaços culturais. $O$ instrumento de planejamento tem o papel de estabelecer a continuidade nos processos de apropriação dos espaços, incorporando, além das necessidades de manutenção, as referências simbólicas do passado e suas potencialidades futuras. Assim, a identificação dos órgãos e dos profissionais envolvidos no contrato de manutenção da iluminação dos patrimônios culturais da cidade, pode mostrar que as orientações adequadas sobre o uso da luz pode trazer o despertar da consciência de preservação da memória e da história dos patrimônios culturais, propiciando juntamente a qualidade de vida aos cidadãos.

\section{ILUMINAÇÃO DOS MONUMENTOS}

No campo da iluminação dos monumentos históricos, são observadas várias polêmicas quanto ao uso das luzes que deformam a leitura arquitetônica, distanciando o conceito proposto pela obra. A luz tem sido usada na revitalização de prédios e cidades antigas, dando ênfase a detalhados elementos simbólicos, artísticos e poéticos mediante a comunicação da luz.

A luz torna-se central na percepção dos ambientes. Na aplicabilidade de uma metodologia coerente com as características da obra, é possível com a iluminação produzir efeitos diversos, como melhor visibilidade noturna do patrimônio, aumentando a segurança e evitando a depredação do local.

O plano diretor de iluminação de uma cidade deve nortear as propostas de valorização do patrimônio cultural, ou seja, tratar a iluminação como uma ferramenta para promover a conscientização da importância de sua preservação e, com isso, elevar questões de desenvolvimento social, cultural e econômico da cidade. 
O movimento de patrimonialização com o avanço do conhecimento científico e tecnológico tem caracterizado o patrimônio cultural como objeto de influência na sociedade atual. A própria expressão já revela múltiplos significados, como no caso do aspecto genérico atribuído ao bem arquitetônico preservado ou tombado, que em algumas formas se cristaliza diante das práticas oficiais que atendem a uma reprodução ideológica distante da realidade contemporânea. Como afirma Choay (2006, p. 11),

em nossa sociedade errante, constantemente transformada pela mobilidade e ubiquidade de seu presente, patrimônio histórico tornou-se uma das palavras-chave da tribo midiática. Ela remete a uma instituição e a uma mentalidade.

$\mathrm{Na}$ relação entre o patrimônio cultural e a sociedade atual vê-se a necessidade de um novo sentido por intermédio da experimentação do presente, que pode ser ensaiada na prática social da relação do indivíduo com o tempo, o espaço e o objeto, para que assim possa suscitar diferentes olhares, no caminhar de novas experiências sensórias perante o patrimônio cultural. O modo como as coisas estão sendo lidas e escritas passa por uma constante mudança. A interpretação e compreensão do mundo atual precisam ser condicionadas e transmitidas com a música, com o design, trazendo novos elementos de abordagem e análise, transformando a percepção em novas oportunidades de interação em decorrência das distintas áreas do conhecimento.

Conforme Yúdice (2004, p. 33), "existem grande interesse internacional pela cultura e grandes somas para serem investidas. No entanto, somente receberão investimentos os seguimentos que gerarem retorno". A cultura está sendo crescentemente dirigida como um recurso para a melhoria sociopolítica e econômica. No presente contexto, a questão política para o seu desenvolvimento está muito ligada à geração de valores. As ações devem estar pautadas nos resultados que se quer atingir.

Alerta Santana (1999 apud YÚDICE, 2004, p. 32): “A cultura pela cultura, seja lá o que isso represente, nunca receberá fomentos a não ser que possa oferecer uma forma indireta de retorno". Na atual conjuntura, a prática baseia-se na preservação dos suportes de memória, mas essa prática somente é possível com a sua conversão em atividades comerciais que atinjam indicadores de retorno, sejam eles por meio de incentivos fiscais ou da comercialização institucional com valor publicitário. Esses dados precisam estar atrelados a dados quantitativos que avaliem 
o retorno do investimento à sociedade e ao estado, para assim justificar meios para a valorização de tais espaços culturais.

Há uma discussão em torno da transformação da cultura contemporânea na qual se moldou a própria lógica do capitalismo de hoje. Essa culturalização da economia não aconteceu de maneira natural; ela foi cuidadosamente coordenada por meio de acordos comerciais e de propriedade intelectual, como o General Agreement on Tariffs and Trade (GATT, em português, Acordo Geral de Tarifas e Comércio) e a Organização Mundial do Comércio (OMC), de leis que controlam o movimento do trabalho mental e físico. Em outras palavras, a nova fase do crescimento econômico, a economia cultural, também é uma economia política (YÚDICE, 2004, p. 35).

Os interesses políticos têm pontos em comum, e esse poder de influência ligado à cultura domina a sociedade. Diante desse cenário, as recomendações atuais em prol de implementações de programas sustentáveis, com energias renováveis, visam contribuir social e economicamente com a sociedade. Com a exposição de modelos coordenados pelo Programa Cidades Sustentáveis (2013), contribuiu-se com o crescimento sustentável das cidades, que nessa óptica se torna um bem comum necessário à população. Perante esse processo, ressignifica-se o presente, para criar novas subjetividades a fim de atender às novas demandas sociais. Na atual conjuntura os indicadores de retorno econômico para o estado estão pautados em um método de conversão das atividades comerciais, com incentivos fiscais ou em comercialização institucional, para gerar valor publicitário. Esse cenário mostra uma nova fase do crescimento econômico, com vistas a transformar as atividades culturais em economia política.

Conforme essa abordagem, os lugares de memória fazem parte de um simbolismo que proporciona sentido às regras sociais, buscando a coesão e o equilíbrio do grupo. Para Nora (1993), os lugares de memória são espaços criados pelo indivíduo contemporâneo diante da crise atual. Com esses espaços eles se identificam, se unificam e se reconhecem como agentes de seu tempo. Ocorre, então, a tão desejada volta dos sujeitos: a atomização de uma memória geral em memória privada dá à lei da lembrança um intenso poder de coerção interior.

Na acepção de Nora (1993), os lugares de memória são uma tentativa de reunificar a fragmentação do indivíduo na contemporaneidade, como um meio de acessibilidade a um padrão formador, diante da perda da memória que fragiliza sua própria história, com o reencontro com o pertencimento para legitimar o presente. 
Com essa reflexão, têm-se fluxos globais de informação, tecnologia, mercadorias, pessoas e capitais. A luz dos monumentos fomenta novos conceitos para dar conta da multiplicidade de memória. De acordo com Gonçalves (2005, p. 33),

\begin{abstract}
a iluminação urbana de conjuntos históricos que remete à memória coletiva é o conjunto de fatos e detalhes históricos, sociais e artísticos que fazem parte das lembranças e recomendações passadas comuns a um grupo social no presente.
\end{abstract}

Essa referência é fundamental para a compreensão da paisagem noturna. $\mathrm{O}$ embelezamento da cidade deve estar pautado em questões sustentáveis, como eficiência energética e gestão de iluminação.

A ideia de iluminar o patrimônio cultural traz a possibilidade de transformar a paisagem, resgatando a identidade noturna do local, de modo a favorecer a ambiência que remete a história da cidade. Os métodos a serem empregados na elaboração do plano diretor vislumbram um caminho para a valorização do patrimônio ambiental noturno. As soluções direcionadas com base em um plano diretor configuram uma resposta à diversidade de paisagens construídas pelo homem, com o intuito único de preservar a memória do lugar e garantir o melhor uso desse espaço. O plano diretor de iluminação urbana orienta-se mediante uma política qualitativa da paisagem urbana, pautando-se em um estudo multidisciplinar que incorpora a pesquisa sobre o histórico do lugar a fim de resguardar a ambiência da época, permitindo conforto e segurança de maneira sustentável.

A luz tem uma função estrutural a desempenhar; ela é, em efeito, o componente fundamental do olhar do cidadão. A luz orienta, destaca, esconde, transforma, integra, isola. O complemento da luz, a sombra, trabalha em sintonia, para melhor sublinhar ou esconder, descobrir ou dissimular. Luzes e sombras estarão transformando profunda e rapidamente a visão das cidades neste século. $O$ interesse em iluminar os monumentos, as esculturas e as fachadas aos quais se atribui importância, seja afetiva ou cultural, reflete na valorização dos cidadãos por sua cidade, pois a luz ajuda a destacar aquilo que se quer apreciar. A iluminação dos monumentos fabrica imagens, comunica e, principalmente, recria os espaços culturais.

A memória viva do patrimônio cultural permite pensar em estratégias para a reutilização desses espaços, contemplando a integração social na vida 
contemporânea. O patrimônio cultural é visto em um jogo social de interesses por esse bem cultural de alta rentabilidade ao estado. Na ideia de Choay (2006, p. 226),

\begin{abstract}
a 'embalagem' que se dá ao patrimônio histórico urbano tendo em vista seu consumo cultural, assim como o fato de ser alvo de investimentos do mercado imobiliário de prestígio, tende a excluir dele as populações locais ou não privilegiadas e, com elas, suas atividades tradicionais e modestamente cotidianas.
\end{abstract}

A experiência de envolvimento do indivíduo com o patrimônio cultural no seu contexto social permite um novo sentido para os espaços culturais que muitas vezes vai além do significado memorial e histórico, ao despertar sensível para a construção subjetiva do tempo no presente.

A ideia de iluminar o patrimônio cultural traz a possibilidade de transformar a paisagem, resgatando a identidade noturna do local, favorecendo a ambiência que remete à história da cidade. Os métodos a serem empregados na elaboração do plano diretor buscam soluções que atendam à diversidade de paisagens construídas pelo homem, com o intuito único de preservar a memória do lugar e garantir o melhor uso desse espaço. O planejamento noturno de orientar uma política qualitativa da paisagem urbana, pautado em um estudo multidisciplinar que incorpora a pesquisa sobre o histórico do lugar, resguarda a ambiência da época, permitindo conforto e segurança de maneira sustentável.

No movimento noturno, as pessoas não podem se sentir agredidas pela luz. As iluminações desuniformes em diferentes lugares, que não correspondem com a cultura local, tornam o processo como um todo inviável. No planejamento de uma iluminação uniforme, colaboram para a construção e o entendimento da diversidade, permitindo manter as diferenças de abordagens sociais e culturais.

A interpretação do espaço arquitetônico deve estar relacionada à arte, pois uma iluminação ruim pode afetar diretamente o ambiente. $O$ projeto de iluminação deve ser desenvolvido com as características do ambiente, e a profundidade e a cor devem traduzir a interpretação arquitetônica. Com a imaginação do espaço a ser iluminado, o posicionamento inicial deve ser no lugar de quem concebeu a obra. Assim, a iluminação do patrimônio cultural instaura mais um sentido na atribuição da sociedade local: os critérios e valores a serem seguidos precisam estar ligados a campos de conhecimentos especializados, seja na arquitetura, no urbanismo, na arte, na história, entre outros, orientando as atividades públicas e sociais que validam os valores e as concepções no reconhecimento da valorização dos bens culturais. 
O uso da luz como forma de instrumento, valorização, conservação e organização do espaço cultural assegura a melhor fruição da paisagem noturna. A afirmação da identidade cultural da cidade expressa a sua configuração no espaço, que no caminho do desenvolvimento econômico deve estar em consonância com o social, para que se possam atingir os objetivos da sustentabilidade. Na preservação do patrimônio histórico, significa preservar valores culturais em processo de transformação permanente. Para que sejam preservados, esses valores em constante atualização são reapropriados pela sociedade, mediante práticas cotidianas. Não se deve confundir a preservação do patrimônio cultural com a preservação do passado; o passado é justamente aquilo que não deve ser preservado, mas ressignificado no presente.

Nesse sentido, o engajamento social na problemática de preservação e reconhecimento do valor histórico e cultural do patrimônio seria maior, tendo em vista um local valorizado com uma iluminação que enalteça suas características construtivas, possibilitando até mesmo a introdução de outros serviços, atraindo mais visitação no período noturno. A discussão possibilita repensar os métodos empregados no plano diretor de iluminação, tendo como abordagem específica o patrimônio cultural, em que preconiza aspectos simbólicos e práticos capazes de contribuir para o fortalecimento da cidadania na apropriação e aproximação às referências do passado, transformando o patrimônio cultural no espaço.

\section{CONSIDERAÇÕES FINAIS}

A relação entre o passado e o presente instiga o fortalecimento da identidade cultural, em função do conhecimento e da formação dos cidadãos, pautados de maneira substancial no desenvolvimento sustentável. Conforme esta análise deve-se discutir a revitalização dos lugares de memória, para ampliar os espaços de manifestação cultural e de lazer, propiciando a criação de mecanismos de preservação do patrimônio, para que se compreenda nossa diversidade, tornando o patrimônio referência da história.

A iluminação noturna pode também contribuir para a diminuição da violência urbana, já que pela ação permite inibir atos de vandalismo, roubo e agressões nos lugares públicos. O espaço urbano das cidades brasileiras apresenta características que facilitam diferentes práticas ou induzem a elas. Nesse contexto, a ideia a respeito de como estabelecer níveis de iluminação que influam de maneira positiva 
na redução da criminalidade no espaço público permite refletir em como a iluminação é capaz de distinguir equipamentos disponíveis para atender às inúmeras funções. Assim, é importante repensar em integrar os conceitos e as funções da luz urbana por meio de um plano diretor de iluminação, que relacione as distintas necessidades metodológicas em questão no processo de requalificação das cidades, ao considerar a luz como um instrumento de comunicação.

Com o intuito estimular novos olhares sobre a iluminação do conjunto patrimonial e incentivar novas ideias e possibilidades com o uso da luz, com o destaque de elementos referenciais por intermédio da luz, permitiu uma nova expressão de linguagem acerca do patrimônio artístico da cidade e dos pontos afetivos dos cidadãos. A investigação buscou fundamentar os conceitos, constituindo a oportunidade de analisar uma temática atual, ao suscitar novos usos de tecnologias para transmitir a leitura do conjunto patrimonial no espaço público da cidade contemporânea.

\section{REFERÊNCIAS}

ABREU, Regina; CHAGAS, Mário (Orgs.). Memória e patrimônio: ensaios contemporâneos. Rio de Janeiro: DP\&A, 2003.

BRANDSTON, Howard. A essência do design da iluminação. Tradução de Paulo Scarazzato. São Paulo:De Maio, 2011.

CANDAU, Joel. Memória e identidade. São Paulo: Contexto, 2011.

CHOAY, Françoise. A alegoria do patrimônio. Tradução de Luciano Vieira Machado. São Paulo: Editora da Unesp, 2006.

EAGLETON, Terry. A ideia de cultura. Tradução de Sandra Castello Branco. São Paulo: Editora da Unesp, 2005.

FERREIRA, Milton Martins. A evolução da iluminação na cidade do Rio de Janeiro. Rio de Janeiro: Synergia, 2009.

FONSECA, Maria Célia Londres. Para além da pedra e cal: por uma concepção ampla de patrimônio cultural. In: ABREU, Regina; CHAGAS, Mário (Orgs.). Memória e patrimônio: ensaios contemporâneos. Rio de Janeiro: DP\&A, 2003. p. 56-76.

GONÇALVES, Ana Lucia de Almeida. Iluminação urbana: a construção da paisagem noturna de sítios históricos. Lume Arquitetura, n. 20, p. 1-13, 2006. 
diretores de iluminação. O caso do bairro histórico de Paraty. 2005. Tese (Doutorado em Arquitetura e Urbanismo)-Faculdade de Arquitetura e Urbanismo, Universidade de São Paulo, São Paulo, 2005.

NARBONI, Roger. A luz e a paisagem: criar paisagens noturnas. Lisboa: Livros Horizonte, 2003.

NORA, Pierre. Entre memória e história: a problemática dos lugares. Projeto História, São Paulo, n. 10, p. 7-28, dez. 1993.

PROGRAMA Cidades Sustentáveis. Disponível em: $<$ http://www.cidadessustentaveis.org.br/boas-praticas/energia-limpa-em-portugal>. Acesso em: 15 maio 2013.

SACHS, Ignacy. Caminhos para o desenvolvimento sustentável. Rio de Janeiro: Garamond, 2002.

YÚDICE, George. A conveniência da cultura. In: YÚDICE, George. A conveniência da cultura: usos da cultura na era global. Tradução de Marie-Anne Kremer. Belo Horizonte: Editora da UFMG, 2004. p.25-64. 